Article

\title{
An Uncertainties Simulation Model Applied to an Automated Laminar Flowmeter
}

\author{
António Pedro ${ }^{1}$, Teresa Morgado $2,3,4, *$ (D) and Helena Navas ${ }^{1,3}$ (D) \\ 1 DEMI-Department of Mechanical and Industrial Engineering, FCTNOVA, 1900 Lisbon, Portugal; \\ antonioagpedro@gmail.com (A.P.); hvgn@fct.unl.pt (H.N.) \\ 2 LNEC-Laboratório Nacional de Engenharia Civil, 1900 Lisbon, Portugal \\ 3 UNIDEMI-Research and Development Unit in Mechanical and Industrial Engineering, FCTNOVA, \\ 1900 Lisbon, Portugal \\ 4 IPT—Polythecnic Institute of Tomar, 2300 Tomar, Portugal \\ * Correspondence: tmorgado@ipt.pt; Tel.: +351-21844-3434
}

Received: 24 September 2019; Accepted: 22 January 2020; Published: 29 January 2020

\begin{abstract}
Aircraft oxygen regulators are a normally used specialized test bench designed to perform tests to the regulators during its work conditions. The tests are performed placing the regulator in the barometric chamber, where low pressure conditions are forced to simulate altitude conditions and then a flow is forced on the output of the regulator to simulate the inhalation of the user. The relevant test flows are measured by laminar flowmeters. These flowmeters are meant to measure the flowrate at pressures correspondent to altitudes between sea level altitude and fifty thousand feet. In this work a way was studied to automate laminar flowmeters used on oxygen regulator test benches. For this purpose, was developed a data acquisition system (DAS) using a microcontroller board and two microelectromechanical systems-MEMSs (a pressure and temperature sensor and a differential pressure sensor). Since these MEMSs did not have factory calibration, they were calibrated in this study. The automated flowmeter was also calibrated. To estimate the error of flow rate measured by this solution, an uncertainties simulation model based on the Monte Carlo method and several calibrations were performed. According to the automated flowmeter calibration, the uncertainty obtained $( \pm 0.45 \% \mathrm{fs})$ is accepted, but the authors only recommend its use for actual volumetric flowrate measurements.
\end{abstract}

Keywords: aircraft oxygen system; test bench; automated laminar flowmeter; Monte Carlo method; calibration; uncertainty; air data test set

\section{Introduction}

The oxygen equipment of an aircraft is the first line of defense against the potentially lethal effects of hypoxia and carbon monoxide poisoning. It is the pilot's responsibility that all aboard the aircraft-crewmembers and passengers—know how to use this life-saving equipment safely and efficiently [1].

Most oxygen systems are composed of a storage system (containers), delivery system and mask or nasal cannula. The oxygen delivery system, also known as an oxygen regulator can be one of three types: continuous flow-delivering continuous flow of oxygen from the storage to the mask $(28,000$ feet and lower); diluter demand: giving the user oxygen on-demand (during inhalation) stopping the flow when the demand ceases (during exhalation) to conserve oxygen (altitudes up to 40,000 ) and pressure demand-providing oxygen under positive pressure to over-inflate the lungs (altitudes above 40,000 feet) $[2,3]$.

Aircraft components require periodical maintenance, repair and overhaul (MRO) activity. For oxygen regulators $\mathrm{MRO}$ is normally used a specialized test bench designed to perform tests to the 
regulators during its work conditions. The test bench is composed of a barometric chamber, a vacuum pump, an altimeter and several flowmeters [4]. The tests are performed placing the regulator in the barometric chamber, where low pressure conditions are forced to simulate altitude conditions and then a flow is forced on the output of the regulator to simulate the inhalation of the user [5]. The relevant test flows are measured by laminar flowmeters [6].

In this work a way was studied to automate laminar flowmeters used on oxygen regulator test benches. The flowmeters studied have particular requirements of accuracy established by the technical documentation delivered by the test bench manufacturer ( $1 \%$ full scale- $\mathrm{fs}$ ). This flowmeter is meant to measure flowrate at pressures correspondent to altitudes between sea level altitude and fifty thousand feet. So, in order to achieve precise measurements, they should be corrected considering the pressure and temperature changes. At the core of this work, the correspondence between altitude and pressure was made in accordance to the U.S. Standard Atmosphere [3]. To estimate the error of the flow rate measured by this solution, an uncertainties simulation model and several calibrations were performed. The simulation model was based on the Monte Carlo method. These calibrations were made in accordance with the Guide to the Expression of Uncertainty in Measurement-GUM [7]. In this work, was also developed a data acquisition system (DAS) using a microcontroller board and two microelectromechanical systems-MEMSs. Since these MEMS did not have factory calibration, the uncertainty measurement study was performed. A methodology was developed to test the accuracy of the automated laminar flowmeter.

\section{Theoretical Fundaments: Laminar Flowmeters}

Laminar flowmeters are a well-known kind of differential pressure-based flow measurement devices mainly used for measuring low flow rates of gases and liquids.

A laminar flowmeter is composed of a laminar flow element and a differential pressure gauge or transducer. The laminar flow element ensures that the flow passing through the flowmeter is in laminar condition. In this condition the viscous forces, generated by internal friction of the fluid, overcome the inertial forces and therefore the dominant mechanism for resistance to fluid motion is friction against the surrounding walls [8].

The pressure drop $(\Delta p)$ caused by fluid friction between two points separated by a distance $\Delta x$ along a pipe in a laminar flow regime is quantifiable, and can be expressed by the Hagen-Poiseuille equation (Equation (1)) [9].

$$
\Delta p=\frac{128 \mu Q \Delta x}{\pi D^{4}}
$$

where $D$ is the pipe internal diameter, $\mu$ the fluid's viscosity and $Q$ the volumetric flow rate.

Equation (1) establishes that for a laminar flow there is a linear relationship between the flow rate and developed pressure drop. A major drawback of this type of flowmeter, however, is its dependence on fluid viscosity, which in turn is mostly dependent on fluid temperature. Thus, any laminar flowmeter requires some form of temperature compensation to obtain precise measurements [4]. In Figure 1 there is a scheme of a longitudinal and a transversal cut of a laminar flowmeter.

The assumptions of the Hagen-Poiseuille equation (Equation (1)) [10] are:

1. The flow has negligible kinetic energy,

2. The flow is laminar and steady,

3. The capillary is straight and has a uniform, circular cross section,

4. The fluid is incompressible and its density is constant,

5. The fluid is Newtonian,

6. The temperature of the fluid is constant and viscous heating is negligible,

7. There is no slip at the wall of the capillary.

This is a simplistic model. 


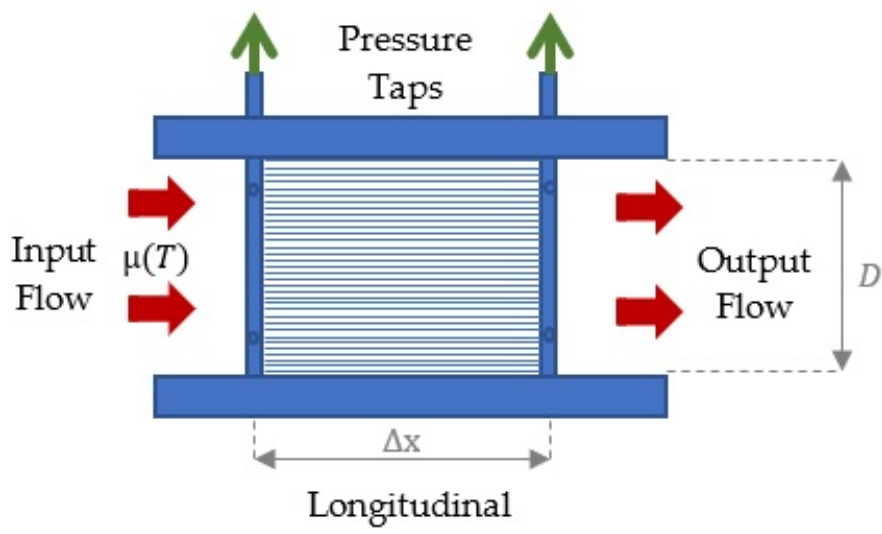

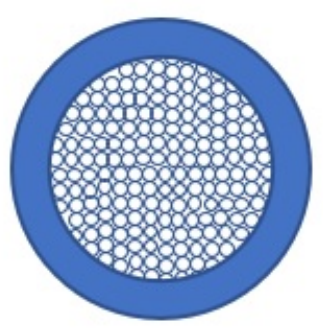

TransversalCut

Figure 1. Laminar flowmeter.

In real situations, it is natural that some of these conditions cannot be met and therefore errors arise in the flow measurement. The practical models used by experimentalists must correct errors arising from a breach of the conditions listed. According to the practical model adopted in this work, each laminar flowmeter has its calibration curve that is generated using a quadratic Equation (2) [11]. This equation is only valid for temperature and pressure at standard conditions (at sea level: $T=15^{\circ} \mathrm{C}$ and $p=1013,25$ mbar).

$$
Q=\left[B \times \Delta p+C \times(\Delta p)^{2}\right],
$$

where $B$ and $C$ are calibration constants.

The actual volumetric flowrate, $Q_{a}$, can be obtained by measuring the differential pressure $(\Delta p)$ across the laminar flow element and the temperature $(T)$ of the inlet fluid. This flow rate can be obtained by the Equation (3).

$$
Q_{a}=\left[B \times \Delta p+C \times(\Delta p)^{2}\right] * \frac{\mu_{s t d}}{\mu_{a}},
$$

where $\mu_{a}$ is the actual viscosity of the fluid and $\mu_{s t d}$ the viscosity of the fluid at standard temperature.

The word "standard" when associated with flow rate, means that the flow rate has been normalized to an assigned standard pressure and temperature [7]. If the standard volumetric flowrate is desired it can be obtained by multiplying the actual volumetric flowrate by the pressure and temperature ratios:

- $\quad$ standard temperature $\left(T_{\text {std }}\right)$ /actual temperature $\left(T_{a}\right)$,

- $\quad$ and actual pressure $\left(p_{a}\right) /$ standard pressure $\left(p_{s t d}\right)$.

This way, the standard volumetric flowrate can be obtained by Equation (4).

$$
Q s t d=\left[B \times \Delta p+C \times(\Delta p)^{2}\right] \times \frac{\mu_{s t d}}{\mu_{a}} \times \frac{T_{s t d}}{T_{a}} \times \frac{p_{a}}{p_{s t d}} .
$$

\section{Experimental Proceeding}

The process of measuring an electrical or physical phenomenon is called data acquisition (DAQ). A DAQ system is normally composed by one or more sensors, a DAQ measurement device or hardware and a computer with programmable software as shown in Figure 2 [4].

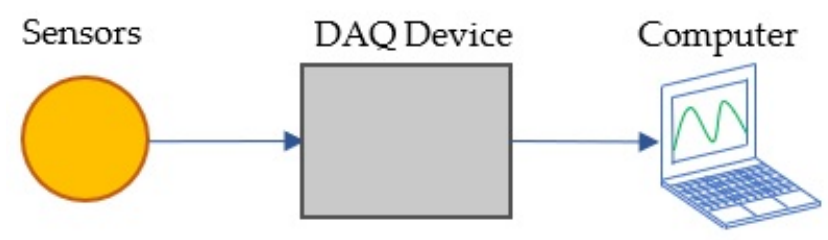

Figure 2. Parts of a data acquisition (DAQ) system. 
The DAQ system used to automate the laminar flowmeters in this work was composed by: two sensors (an absolute pressure and temperature sensor and a differential pressure sensor), an Arduino microcontroller board and a computer (Figure 2).

In Figure 3 the solution's is presented with all the components: The MEMS capture the three input variables $(p, T$ and $\Delta p)$. The Arduino acquires the signals from the sensors, stabilizes them if necessary and converts them. These signals are sent to the computer where they are processed according to information programmed in LabVIEW and finally the desired outputs $\left(Q, Q_{a}\right.$ and $\left.Q s t d\right)$ are obtained.

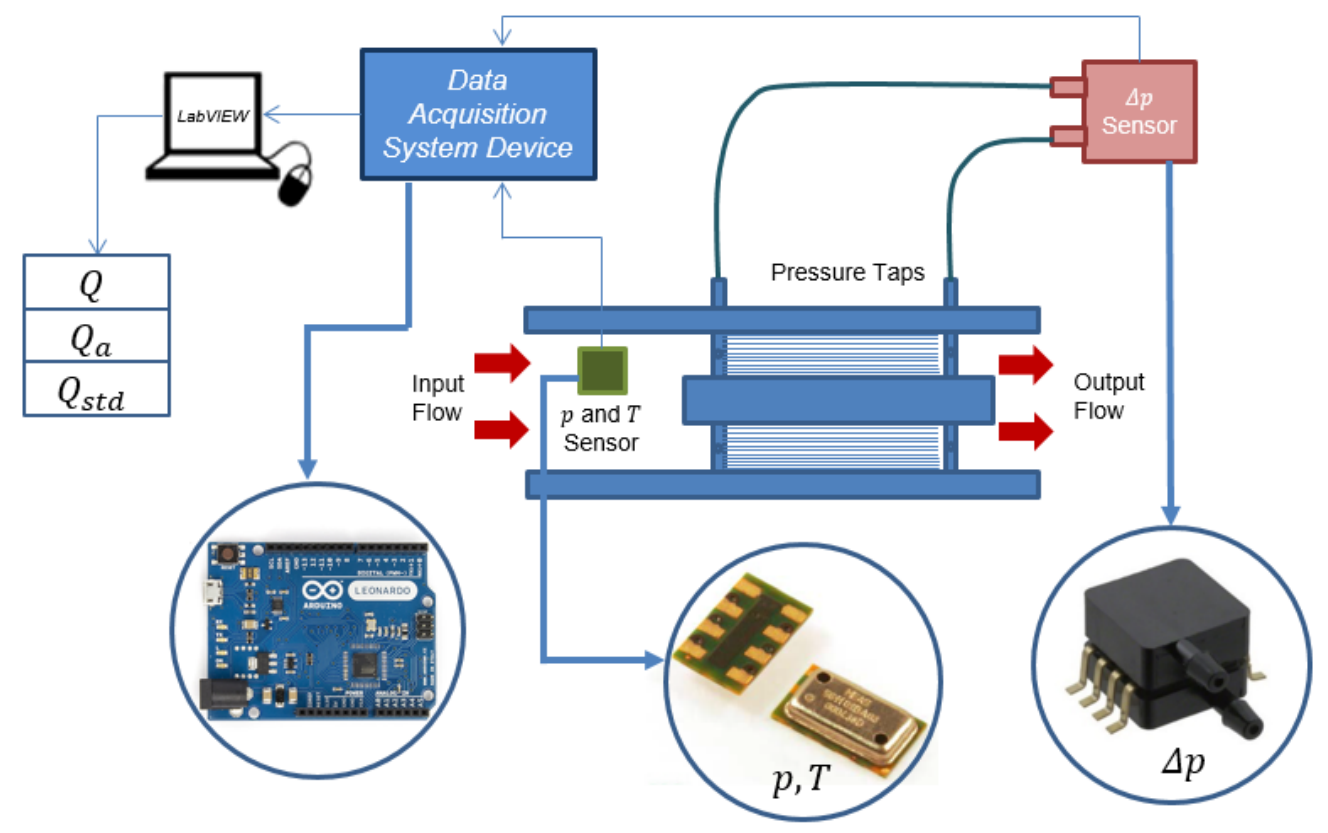

Figure 3. Solution's setup.

A MS5611-01BA03 barometric pressure sensor, with a stainless steel cap [12] was used, to measure pressure and temperature (see Figure 3). This is a new generation of a high resolution altimeter sensor, which the specifications are presented in Table 1. A differential and gauge, integrated pressure sensor, MPXV5004DP, was used to measure the pressure drop [13], and the respective specifications are presented in Table 2. The MPXV5004DP MEMS combines a highly sensitive implanted strain gauge with advanced micromachining techniques, thin-film metallization and bipolar processing to provide an accurate, high level analog output sign that is proportional to the applied pressure [13]. The data acquisition system used the micro controller board Arduino Leonardo [14] based on the Atmega32u4 microprocessor [15]. The Arduino Leonardo has 20 digital input/output pins, $16 \mathrm{MHz}$ crystal oscillator, a micro USB connection [14]. In Table 3 are presented the Atmega32u4 principal specifications.

Table 1. MS5611-01BA03 technical data.

\begin{tabular}{cccc}
\hline Sensor Performance $\left(V_{S}=3 \mathbf{V}\right)$ & Minimum & Maximum & Unit \\
\hline Pressure Range & 10 & 1200 & $\mathrm{mbar}$ \\
Pressure Accuracy $\left(25^{\circ} \mathrm{C} ; 750 \mathrm{mbar}\right)$ & -1.5 & +1.5 & $\mathrm{mbar}$ \\
Error Band $\left([-20,+85]{ }^{\circ} \mathrm{C},[450,1100]\right.$ mbar $)$ & -2.5 & +2.5 & $\mathrm{mbar}$ \\
Temperature Range & -40 & +85 & ${ }^{\circ} \mathrm{C}$ \\
Temperature Accuracy & -0.8 & +0.8 & ${ }^{\circ} \mathrm{C}$ \\
\hline
\end{tabular}


Table 2. MPXV5004DP technical data.

\begin{tabular}{|c|c|c|c|c|}
\hline $\begin{array}{l}\text { Operating Characteristics } \\
\qquad\left(V_{S}=5.0 \mathrm{~V}\right)\end{array}$ & Minimum & Tipic & Maximum & Unit \\
\hline Pressure Range & 0 & - & 400 & $\mathrm{~mm} \mathrm{H}_{2} \mathrm{O}$ \\
\hline Full Scale Span $\left(V_{F S S}\right)$ & - & 3 & - & $\mathrm{V}$ \\
\hline $\begin{array}{c}\text { Accuracy } \\
{[0,100] \mathrm{mm} \mathrm{H}_{2} \mathrm{O}[10,60]^{\circ} \mathrm{C}}\end{array}$ & -1.5 & - & +1.5 & $\begin{array}{c}\% V_{F S S} \\
\text { (with autozero) }\end{array}$ \\
\hline $\begin{array}{c}\text { Accuracy } \\
{[100,400] \mathrm{mm} \mathrm{H}_{2} \mathrm{O}[10,60]^{\circ} \mathrm{C}}\end{array}$ & -2.5 & - & +2.5 & $\begin{array}{c}\% V_{F S S} \\
\text { (with autozero) }\end{array}$ \\
\hline $\begin{array}{c}\text { Accuracy } \\
{[0,400] \mathrm{mm} \mathrm{H}_{2} \mathrm{O}[10,60]^{\circ} \mathrm{C}}\end{array}$ & -6.25 & - & +6.25 & $\begin{array}{c}\% V_{F S S} \\
\text { (without autozero) }\end{array}$ \\
\hline
\end{tabular}

Table 3. Atmega32u4 technical data.

\begin{tabular}{cc}
\hline \multicolumn{1}{c}{ Features } \\
Work Voltage & \\
Input Voltage (recommended) & $5 \mathrm{~V}$ \\
Input Voltage (limit) & $7-12 \mathrm{~V}$ \\
Digital I/O Pin & $6-20 \mathrm{~V}$ \\
Analogic Input pin & $20(7 \mathrm{PWM})$ \\
Intensity by pin & 12 \\
Intensity in pin 3.3 V & $40 \mathrm{~mA}$ \\
Flash Memory & $50 \mathrm{~mA}$ \\
SRAM & $32 \mathrm{~KB}\left(4 \mathrm{~KB}\right.$ bootloader $\left.{ }^{2}\right)$ \\
EEPROM & $25 \mathrm{~KB}$ \\
Maximum Frequency & $1 \mathrm{~KB}$ \\
\end{tabular}

\section{Calibrations}

In order to determinate the real uncertainty of measurement associated with each MEMS and to with automated flowmeter, calibrations were performed to each device separately.

The calibrations were performed according to the Guide to the Expression of Uncertainty in Measurement-GUM [7].

A Ruska 7750i Air Data Test Set (ADTS) [16] was used, for absolute and differential pressure calibration and a thermal mass flowmeter for volumetric flow rate calibration. The model $7750 \mathrm{i}$ is indicated for avionics instrumentation and represented the latest generation ADTS, having unequalled precision and long term stability with the latest pressure control technology, provides high performance measurement and control of all air data parameters [16].

For the calibration of the absolute pressure sensor, the sensor was placed in a barometric chamber where standard pressures were forced by the vacuum pump of the ADTS (see Figure 4). Five different pressures were forced inside the chamber, which, according to the U.S. Standard Atmosphere [3], refer to the altitude of: sea level, 10, 20, 30, 40 and 50 feet. Table 4 represents the calibration sheet of this sensor. 


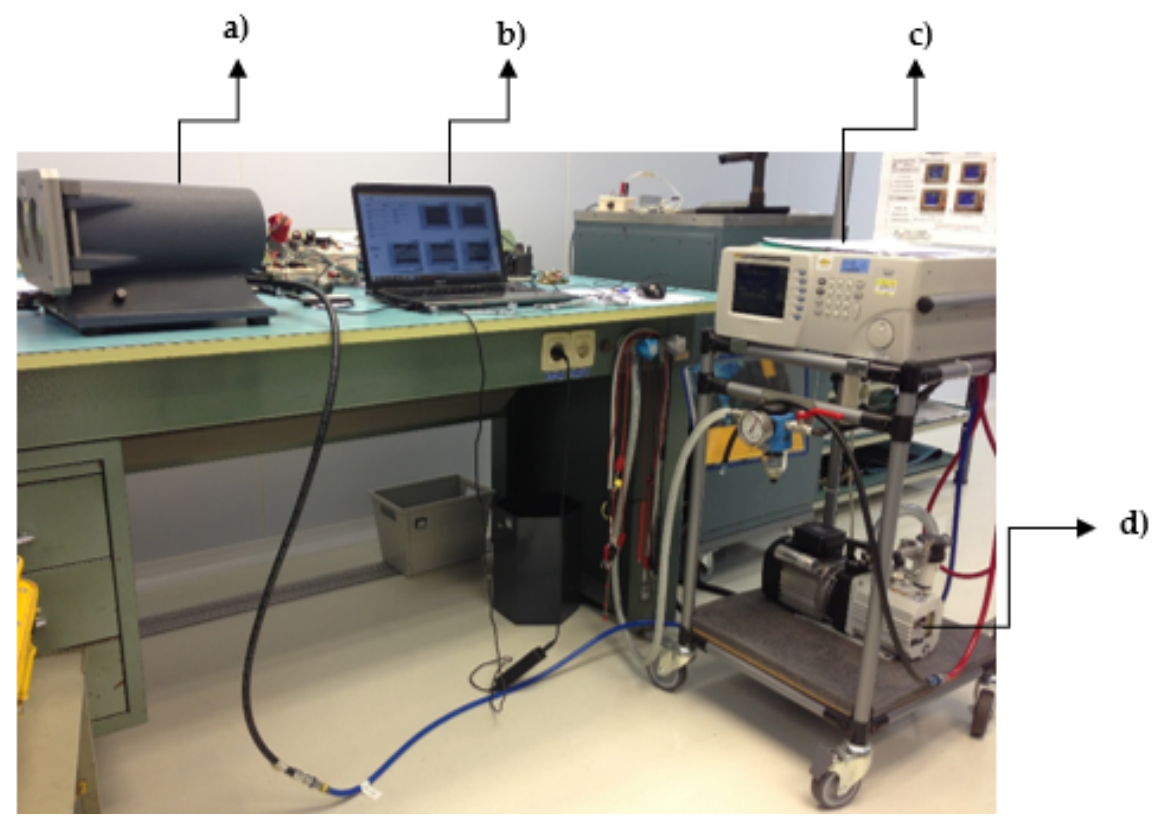

Figure 4. Calibration' setup: (a) barometric chamber; (b) laptop computer; (c) Air Data Test Set (ADTS) and (d) vacuum pump.

Table 4. Absolute pressure sensor calibration sheet.

\begin{tabular}{cccc}
\hline Reference Pressure (mbar) & Sensor Reading (mbar) & $\mathbf{k}$ & Uncertainty $( \pm$ mbar) \\
\hline 1013.250 & 1013.18 & 2.02 & 0.16 \\
696.817 & 696.32 & 2.07 & 0.15 \\
465.633 & 464.49 & 2.03 & 0.1 \\
300.896 & 299.18 & 2.17 & 0.13 \\
187.539 & 185.43 & 2.52 & 0.13 \\
155.972 & 113.66 & 2.2 & 0.08 \\
\hline
\end{tabular}

Considering the calibration of the differential pressure sensor the same ADTS was used, connected to the positive pressure tap. This calibration is expressed in Table 5.

Table 5. Differential pressure sensor calibration sheet.

\begin{tabular}{cccc}
\hline Reference Pressure (in $\left.\mathrm{H}_{\mathbf{2}} \mathbf{O}\right)$ & Sensor Reading $\left(\mathbf{i n} \mathbf{H}_{\mathbf{2}} \mathbf{O}\right)$ & $\mathbf{k}$ & Uncertainty $\left( \pm\right.$ in $\left.\mathbf{H}_{\mathbf{2}} \mathbf{O}\right)$ \\
\hline 1 & 0.97 & 2.65 & 0.03 \\
5 & 4.94 & 2.2 & 0.04 \\
10 & 9.93 & 2.28 & 0.04 \\
14 & 13.91 & 2.65 & 0.03 \\
\hline
\end{tabular}

The calibration of the automated flowmeter was performed placing the two flowmeters in series (the thermal mass flowmeter and the automated flowmeter). The tests were performed with air at three different pressures: sea level, $30 \mathrm{kft}$ and $50 \mathrm{kft}$. In Table 6 the calibration sheet at sea level is presented. At this pressure was obtained the maximum uncertainty of measurement. 
Table 6. Automated flowmeter calibration sheet at sea level pressure.

\begin{tabular}{cccc}
\hline Reference Flowrate (slpm) & Flowmeter Reading (slpm) & k & Uncertainty ( \pm slpm) \\
\hline 5.953 & 5.7 & 2.01 & 0.65 \\
50.05 & 49.6 & 2.01 & 0.59 \\
95.975 & 96.5 & 2.04 & 0.6 \\
137.85 & 138.4 & 2.18 & 0.67 \\
\hline
\end{tabular}

The maximum flowrate uncertainty of measurement obtained was \pm 0.67 standard litters per minute that correspond to a relative uncertainty of $\pm 0.45 \%$ full scale.

\section{Uncertainties Simulation Model}

In order to predict the measurement error of the automated flowmeter several simulations were executed. For that purpose, was performed an uncertainty simulation model, based on the Monte Carlo method, taking as premises two different scenarios for the MEMS uncertainties of the measurement: one based on the manufacturers information (Simulation 1) and another based on the results of the calibrations performed (Simulation 2). The software used for these simulations was Matlab.

In these simulations random values were generated for the input variables $(p, T$ and $\Delta p)$ and their respective errors $\left(u_{T}, u_{p}\right.$ and $\left.u_{\Delta p}\right)$, within their established ranges, and subsequently values of the output data were calculated $\left(Q_{a}\right.$ and $\left.Q_{s t d}\right)$ and also their respective errors $\left(u_{Q_{a}}\right.$ and $\left.u_{Q_{s t d}}\right)$.

In each simulation were selected the maximum errors observed for the output data.

A non-air-conditioned room where there were established ranges for the input variables and for their respective error was ensured (Table 7). As has been said before, in simulation 1 the ranges of error were established according to the data sheets of the MEMS, provided by its manufacturers; in simulation 2 the ranges of error were established according to the results obtained on MEMS calibrations. For the generation of the input variables and respective errors the rand function of Matlab was used. This function uses rectangular distribution in the generation of random value within its established range.

Table 7. Input variables and respective errors.

\begin{tabular}{cccc}
\hline Variables & Min & Max & Unit \\
\hline$p$ & 11,597 & 102,000 & $\mathrm{~Pa}$ \\
$T$ & 263.15 & 313.15 & ${ }^{\circ} \mathrm{K}$ \\
$\Delta p$ & 0 & 10 & inH2O \\
Errors (Manufacturers) & Min & Max & Unit \\
$u_{T}$ & -0.8 & 0.8 & ${ }^{\circ} \mathrm{K}$ \\
$u_{p}$ & -250 & 250 & $\mathrm{~Pa}$ \\
$u_{\Delta p}(\Delta p<3.94$ inH2O) & -0.18 & 0.18 & inH2O \\
$u_{\Delta p}(\Delta p>3.94$ inH2O) & -0.3 & 0.3 & inH2O \\
Errors (Calibrations) & Min & Max & Unit \\
$u_{p}$ & -16 & 16 & Pa \\
$u_{\Delta p}$ & -0.04 & 0.04 & inH2O \\
\hline
\end{tabular}

\section{Results and Discussion}

Tables 8 and 9 express the results of simulation 1, based on the manufacturing uncertainty, that maximize the actual volumetric flow rate and the standard volumetric flow rate, respectively. 
Table 8. Simulation 1: actual volumetric flow rate.

\begin{tabular}{ccccccc}
\hline $\begin{array}{c}\boldsymbol{i} \\
\text { Number of Iterations }\end{array}$ & $\begin{array}{c}\Delta p \\
\mathbf{( i n H 2 O )}\end{array}$ & $\begin{array}{c}\boldsymbol{u}_{\Delta p} \\
\mathbf{( i n H 2 O )}\end{array}$ & $\begin{array}{c}\boldsymbol{T} \\
\mathbf{( K )}\end{array}$ & $\begin{array}{c}u_{T} \\
\mathbf{( K )}\end{array}$ & $\begin{array}{c}Q_{a} \\
\mathbf{( 1 p m )}\end{array}$ & $\begin{array}{c}u_{Q_{a}} \\
(\mathbf{\%} \text { fs) }\end{array}$ \\
\hline $10 \mathrm{M}$ & 3.96 & -0.299 & 265.45 & 0.791 & 72.633 & 3.559 \\
- & 3.94 & -0.300 & 263.15 & 0.800 & 72.782 & 3.598 \\
\hline
\end{tabular}

Table 9. Simulation 1: standard volumetric flow rate.

\begin{tabular}{|c|c|c|c|c|c|c|c|c|}
\hline$i$ & $\begin{array}{c}\Delta p \\
(\mathrm{inH} 2 \mathrm{O})\end{array}$ & $\begin{array}{c}u_{\Delta p} \\
(\mathrm{inH} 2 \mathrm{O})\end{array}$ & $\begin{array}{c}T \\
(\mathrm{~K})\end{array}$ & $\begin{array}{l}u_{T} \\
(\mathrm{~K})\end{array}$ & $\begin{array}{c}p \\
(\mathrm{~Pa})\end{array}$ & $\begin{array}{c}u_{p} \\
(\mathbf{P a})\end{array}$ & $\begin{array}{c}Q_{s t d} \\
(\mathrm{slpm})\end{array}$ & $\begin{array}{c}u_{Q_{s t d}} \\
(\% \mathrm{fs})\end{array}$ \\
\hline $10 \mathrm{M}$ & 6.14 & 0.297 & 263.32 & -0.608 & 101,730 & 173.68 & 120.301 & 3.984 \\
\hline- & 3.94 & 0.300 & 263.15 & -0.800 & 102,000 & 250.00 & 80.235 & 4.265 \\
\hline
\end{tabular}

Based on the calibrations uncertainty, Tables 10 and 11 express the results of simulation 2 that maximize the actual volumetric flow rate and the standard volumetric flow rate, respectively.

Table 10. Simulation 2: actual volumetric flow rate.

\begin{tabular}{|c|c|c|c|c|c|c|}
\hline$i$ & $\begin{array}{c}\Delta p \\
(\mathrm{inH} 2 \mathrm{O})\end{array}$ & $\begin{array}{c}u_{\Delta p} \\
(\mathrm{inH} 2 \mathrm{O})\end{array}$ & $\begin{array}{c}T \\
(\mathrm{~K})\end{array}$ & $\begin{array}{c}u_{T} \\
(\mathrm{~K})\end{array}$ & $\begin{array}{c}Q_{a} \\
(1 \mathrm{pm})\end{array}$ & $\begin{array}{c}u_{Q_{a}} \\
(\% \mathrm{fs})\end{array}$ \\
\hline $10 \mathrm{M}$ & 9.94 & 0.039 & 263.15 & -0.778 & 166.89 & 0.636 \\
\hline- & 10.00 & 0.040 & 263.15 & -0.800 & 167.67 & 0.644 \\
\hline
\end{tabular}

Table 11. Simulation 2: standard volumetric flow rate.

\begin{tabular}{|c|c|c|c|c|c|c|c|c|}
\hline$i$ & $\begin{array}{c}\Delta p \\
(\mathrm{inH} 2 \mathrm{O})\end{array}$ & $\begin{array}{c}u_{\Delta p} \\
(\mathrm{inH} 2 \mathrm{O})\end{array}$ & $\begin{array}{c}T \\
(\mathrm{~K})\end{array}$ & $\begin{array}{c}u_{T} \\
(\mathbf{K})\end{array}$ & $\begin{array}{c}p \\
(\mathrm{~Pa})\end{array}$ & $\begin{array}{c}u_{p} \\
(\mathrm{~Pa})\end{array}$ & $\begin{array}{c}Q_{s t d} \\
\text { (slpm) }\end{array}$ & $\begin{array}{c}u_{Q_{s t d}} \\
(\% \mathrm{fs})\end{array}$ \\
\hline $10 \mathrm{M}$ & 9.34 & 0.035 & 264.79 & -0.799 & 100,410 & 12.57 & 178.95 & 1.016 \\
\hline- & 10.00 & 0.040 & 263.15 & -0.800 & 102,000 & 16.00 & 184.84 & 1.107 \\
\hline
\end{tabular}

The results of the MEMS calibration and the maximum errors that their manufactures claim to occur are presented in Table 12. Note that this MEMS do not have factory calibration, so it is natural that their manufacturers supply data with higher values of measurement errors in order to guarantee their clients medium/long time satisfaction.

Table 12. Uncertainty of microelectromechanical systems (MEMSs).

\begin{tabular}{ccc}
\hline MEMS & Calibration & Manufacturer \\
\hline Pressure & $\pm 0.16 \mathrm{mbar}^{2}$ & $\pm 2.50 \mathrm{mbar}$ \\
Differential Pressure & $\pm 0.040 \mathrm{inH}_{2} \mathrm{O}$ & $\pm 0.30 \mathrm{inH}_{2} \mathrm{O}$ \\
\hline
\end{tabular}

The maximum output errors were obtained in simulations that used ten million iterations. However, by analyzing the trend of the variables over each simulation, it was verified that the maximum output errors were obtained when the input values and respective errors take the limit values of their range. So, for this case, the iteration number (i) was negligible.

In Table 13 there are presented the results obtained by the two simulations and by the calibration for the uncertainty of actual and standard volumetric flowrate. As has been said before, this flowmeter had a particular accuracy requirement established by the technical documentation delivered by the test bench manufacturer $( \pm 1 \%$ full scale). 
Table 13. Uncertainty of the actual and standard volumetric flowrate.

\begin{tabular}{cccc}
\hline & Simulation 1 & Simulation 2 & Calibration \\
\hline Actual Volumetric Flowrate & $\pm 3.56 \%$ fs & $\pm 0.64 \% \mathrm{fs}$ & $\pm 0.45 \% \mathrm{fs}$ \\
Standard Volumetric Flowrate & $\pm 4.27 \% \mathrm{fs}$ & $\pm 1.11 \% \mathrm{fs}$ & $\pm 0.45 \% \mathrm{fs}$ \\
\hline
\end{tabular}

So, according to the MEMS manufacturing uncertainty, the automated flowmeter measurement uncertainty was $u_{Q_{a}} \approx \pm 3.6 \%$ fs and $u_{Q_{s t d}} \approx \pm 4.3 \%$ fs. According to the MEMS calibrations uncertainty, the automated flowmeter measurement uncertainty was $u_{Q_{a}} \approx \pm 0.6 \%$ fs and $u_{Q_{s t d}} \approx \pm 1.1 \%$ fs.

\section{Conclusions}

The conclusions taken from the various stages of this work are:

- The data measurement uncertainty given by the sensors manufacturers was higher than the obtained by the calibrations, so all MEMS must be calibrated before installed in the setup.

- The iteration number for simulation 1 and simulation 2 was negligible, because the maximum output errors were obtained when the input values and respective errors took the limit values of their range.

- In simulation 1, it was observed that both the actual volumetric flowrate and standard volumetric flowrate largely exceeded the accuracy requirement ( $\pm 1 \%$ full scale). So, in coherence with the data measurement uncertainty given by the manufacturer this simulation was very conservative.

- In simulation 2 the actual volumetric flowrates maximum error was lower than the accuracy requirement established by the technical documentation delivered by the test bench manufacturer ( $\pm 1 \%$ full scale).

- The maximum error of the standard volumetric flowrate, obtained by simulation 2 , slightly exceeded the accuracy requirement established by the test bench technical manual.

- The automated flowmeter calibration performed according to the Guide to the Expression of Uncertainty in Measurement shows the lowest uncertainty values.

- The measurement uncertainty given by the calibration was lower than the values obtained by both simulations.

- According to the automated flowmeter calibration, the uncertainty obtained $( \pm 0.45 \%$ fs) was accepted by the requirement and therefore recommended for this application.

By analyzing all the results, this automated flowmeter can be used in this test bench, but the authors only recommended its use for actual volumetric flowrate measurements.

Author Contributions: All the authors provide critical feedback and helped shape the research and analysis. A.P. performed the experiments. T.M. and H.N. contributed to the experiments by scientific supervision. A.P. and T.M. wrote the paper first version. T.M. wrote, reviewed and edited. All authors have read and agreed to the published version of the manuscript.

Funding: This research received no external funding

Conflicts of Interest: The authors declare no conflict of interest. 


\section{Abbreviations}

$\begin{array}{ll}\text { fs } & \text { full scale } \\ B, C & \text { calibration constants } \\ D & \text { pipe internal diameter } \\ i & \text { number of iterations } \\ k & \text { expansion factor } \\ \text { ls } & \text { standard liters } \\ P W M & \text { Pulse-Width Modulation } \\ p & \text { pressure } \\ p_{a} & \text { actual pressure } \\ p_{s t d} & \text { standard pressure } \\ Q & \text { volumetric flow rate } \\ Q_{a} & \text { actual volumetric flowrate } \\ Q_{s t d} & \text { standard volumetric flowrate } \\ T & \text { temperature } \\ T_{a} & \text { actual temperature } \\ T_{s t d} & \text { standard temperature } \\ u_{p} & \text { standard uncertainty of the measurand estimate, } p \\ u_{T} & \text { standard uncertainty of the measurand estimate, } T \\ u_{\Delta p} & \text { standard uncertainty of the measurand estimate, } \Delta p \\ u_{Q_{a}} & \text { standard uncertainty of the measurand estimate, } Q_{a} \\ u_{Q_{s t d}} & \text { standard uncertainty of the measurand estimate, } Q_{s t d} \\ V_{S} & \text { Supply Voltage } \\ V_{F S S} & \text { Full Scan Span Voltage } \\ \Delta x & \text { distance between two pressure points } \\ \Delta p & \text { pressure drop } \\ \mu & \text { fluid's viscosity } \\ \mu_{a} & \text { fluid's actual viscosity } \\ \mu_{s t d} & \text { fluid's viscosity at standard temperature } \\ & \end{array}$

\section{References}

1. Brown, J.R.; Salamanca, M.A. Oxygen Equipment Use in General Aviation Operations; Federal Aviation Administration, Civil Aerospace Medical Institute, Aerospace Medical Education Division: Oklahoma City, OK, USA, 2014

2. Federal Aviation Administration (FAA). Cabin Environmental Control Systems. In Aviation Maintenance Technician Handbook-Airframe; Newcastle (Washington): Aviation Supplies and Academics (ASA): Newcastle, WA, USA, 2012; Volume 2.

3. International Civil Aviation Organization (ICAO). US. Standard Atmosphere; US. Government Printing Office: Washington, DC, USA, 1962.

4. Pedro, A. Improvement Study of an Oxygen Regulator-Aircraft Component Test Bench. Master's Thesis, Faculty of Sciences and Technology-Universidade Nova de Lisboa (FCT NOVA), Lisbon, Portuguese, 2016.

5. United States Air Force (USAF). Technical Manual-Maintenance Instructions-Oxygen Equipment; no. T.O. 15X-1-1; Department of the Air Force of the United States: Washington, DC, USA, 2014.

6. Baker, R.C. Flow Measurement Handbook: Industrial Designs, Operating Principles, Performance and Applications; Cambridge University Press: New York, NY, USA, 2005.

7. JCGM 100:2008. Evaluation of Measurement Data-Guide to the Expression of Uncertainty in Measurement. In Joint Commitee for Guides in Metrology, 1st ed.; 2008; Available online: http://doi.org/10.1373/clinchem.2003. 030528 (accessed on 10 January 2019).

8. Pena, F.L.; Deibe, A.D.; Lema, M.R.; Rodriguez, S.V. A new approach to laminar flowmeters. Sensors 2010, 10, 10560-10570. [CrossRef] [PubMed]

9. White, F.M. Fluid Mechanics, 7th ed.; McGraw-Hill: New York, NY, USA, 2011.

10. Wright, J.D.; Cobu, T.; Berg, R.F.; Moldover, M.R. Calibration of laminar flow meters for process gases. Flow Meas. Instrum. 2012, 25, 8-14. [CrossRef] 
11. Meriam. User's Manual Laminar Flow Elements; Meriam: Cleveland, OH, USA, 2015.

12. Measurement Specialties. MS5611-01BA03 Barometric Pressure Sensor, with Stainless Steel Cap; Measurement Specialties TM: Fremont, CA, USA, 2012; Volume 4096, Available online: https://www.te.com/commerce/DocumentDelivery/DDEController?Action=srchrtrv\&DocNm= MS5611-01BA03\&DocType=Data+Sheet\&DocLang=English (accessed on 4 January 2019).

13. NXP Data Sheet: Technical Data. MPxx5004, 0 to $3.92 \mathrm{kPa}$, Differential and Gauge, Integrated Pressure Sensor. Document Number: MPxx504. Rev12.1, 05/2015. Available online: https://www.nxp.com/docs/en/data-sheet/ MPXV5004G.pdf (accessed on 4 January 2019).

14. Arduino. Arduino Leonardo. 2015. Available online: https://store.arduino.cc/leonardo (accessed on 19 September 2016).

15. ATMEL Corporation. ATMEGA32u4 Datasheet: ATmega16/U4/ATmega32U4. 7766BS-AVR-07/08. Available online: https:/html.alldatasheet.com/html-pdf/241057/ATMEL/ATMEGA32U4/153/1/ATMEGA32U4.html (accessed on 19 September 2016).

16. Fluke Corporation. RUSKA 7750i Air Data Test Set Users Manual. PN3963351. USA, 2010. Available online: http://assets.fluke.com/manuals/7750i__umeng0000.pdf (accessed on 19 September 2016).

(C) 2020 by the authors. Licensee MDPI, Basel, Switzerland. This article is an open access article distributed under the terms and conditions of the Creative Commons Attribution (CC BY) license (http://creativecommons.org/licenses/by/4.0/). 